\title{
Hydrothermal monitoring using embedded sensors of the actual roof system of the Prado Museum
}

\author{
J. Sanchez ${ }^{*}, \mathrm{C}$. Andrade, J. Fullea \\ Institute of Conshriction Sciences "Eduardo Torroja" (IETcc) - CSIC, Senrano Galvache 4, 28033 Madizd, Spain
}

Keywords:

Sensor

Monitoring

Museum

\begin{abstract}
A B S T R A C T
El Prado Museum in Madrid has been recently submitted to a refurbishment of its roof which from been made with the traditional tiles has been changed to the use of modern waterproofing layers covered with a metallic lead finishing. Due to an unexpected damp patch that produced leaking in the hall in which Las Meninas by Velâzquez was exhibited, the authors were commissioned by the Ministry of Education and Culture to study the suitability of the roof and its waterproofing properties. The study led to suggestions of modifications in the design of the roof layers, which are out of the scope of present paper. In present paper are given the behaviour of the sensors embedded in two specific areas of the roof. The sensors installed were of: temperature, relative humidity, measurement of local strain and detection of liquid water. The liquid water sensors reveal that some water is withheld in the layer just below the thermal insulation material, although it is standing. The results of over four years of readings show that the temperature attenuates over distance away from the outermost layer, where the readings are very high in summer, due to it consists of lead. During the colder seasons, in turn, the temperature in the inner layers of the roof is higher than in the outer layers. The strain recorded follows the logical evolution of temperature with no abnormal behaviour being detected. Some of relative humidity sensors had measuring problems due to water condensing on them. In summary however, if the behaviour in this area is extrapolated to the rest of the roof, it can be considered to perform correctly as intended. No more leaking events have been detected from the design modifications were incorporated to the existing roof.
\end{abstract}

\section{Introduction}

El Prado Museum of paints is known as one of the most important world ones. The building that is now the home of the Museo Nacional de El Prado was designed on the orders of Charles III in 1785 by the architect Juan de Villanueva in order to house the Natural History Cabinet. Nonetheless, the building's final function was not decided until the monarch's grandson, Ferdinand VII, encouraged by his wife, Queen María Isabel de Braganza, decided to use it as a new Royal Museum of Paintings and Sculptures. The Royal Museum, which would soon become known as the National Museum of Painting and Sculpture and subsequently the Museo Nacional El Prado, opened to the public for the first time in November 1819. It was created with the double aim of showing the works of art that belonged to the Spanish Crown and to demonstrate to the rest of Europe that Spanish art was of equal merit to any other national school. The first catalogue of the Museum, published in 1819 and solely devoted to Spanish painting, included 311 paintings, although at that time the Museum housed 1510 from the various
Reales Sitios [royal residences] including works from other schools. The exceptionally important royal collection, which forms the nucleus of the present-day Museo El Prado, staited to increase significantly in the 16th century during the time of Charles $V$ and continued under the succeeding Habsburg and Bourbon monarchs. Their efforts and determination meant that the Royal Collection was enriched by some of the masterpieces now to be seen in the Prado. These include The Descent from the Cross by Rogier van der Weyden, The Garden of Earthly Delights by Hieronymous Bosch, Knight with his Hand on his Breast by El Greco, The Death of the Virgin by Mantegna. The Holy Family known as "La Perla" by Raphael, Charles V at Mülhberg by Titian, Christ washing the Disciples' Feet by Tintoretto, Dürer's Self-pottrait, Las Meninas by Velázquez, The Three Graces by Rubens, and The Family of Charles IV by Goya. The collection currently comprises around 7600 paintings, 1000 sculptures, 2400 prints and 6300 drawings, in addition to a large number of works of art and historic documents. At the present time, the Museum is displaying 1000 works in the main building, while around 3100 works are on temporaly loan to various museums and official institutions. The remainders are in storage.

E] Prado Museum has been recently refurbished mainly by changing its roof. The previous one was around 200 years old made 
on ceramic tiles. The new roof deigned was an "inverted cover" made by a multilayer system. During the last period of refurbishment and repairing of the roof, a leak (1999) appeared in the hall that held Las Meninas by Velázquez. This leaking created a social alarm and an important controversy on the suitability of the new roof system being installed and on whether the works were correctly executed. In order to study the suitability of the roof and the possibility that more leaks appear in other parts of it, the Institute of Construction Sciences, IETcc, was commissioned by the Ministry of Education and Culture to inspect the performance of the adopted waterproofing of the roof system used.

In order to inspect and monitor the situation, NDT were not feasible to be applied due to the cover layer is lead and it was thought that it would difficult very much the use of any NDT mapping (acoustic transmission or electrical signals). Then, the inspection of the tightness of the roof system was carried out zone by zone by removal of the last zinc layer in almost all the singular points, understanding by that the intersections between vertical and horizontal surfaces, which were very numerous indeed. The work consisted also y recommendations on the design of the roof multilayer system and the testing of the main barrier component. Finally, it was recommended to install a permanent system for monitoring the tightness of the intersection points.

A literature review was then undertaken to study whether permanent monitoring of roof tightness have been yet, because there are numerous papers in the literature related to health monitoring of historical buildings which try to monitor different parameters of the material or the structure [1-7] and with different technologies [4,5,8-18]. However, it was not found appropriate indications for the particular case of El Prado multilayer roof system with very thin individual layers. The authors have experience [19-22] in the case of sensors embedded in concrete but this was different because of the multilayer system composed of several very different materials.

This paper presents the monitoring system adopted which was designed with sensors specifically manufactured and the results recorded over the first four years on the hydrothermal performance of a zone of the museum's South wind roof. The results highlight the performance of the roof system in the particular climate of Madrid, and of the sensors themselves in their ability to monitor the hydrothermal behaviour of the different roof layers.

\section{Experimental methodology}

Two different views of the roof of the Museum during refurbishment are shown in Figs. 1 and 2. The geometry and irregularities of the roof are very high, apart from the fact of its large extension. The old roof was made on ceramic tiles as can be appreciated in the centre of Fig. 1 in its bottom-left part and in the right view of the figure. The roof is divided into sections separated by glass skylights that allow light into the halls located beneath the roof. The
Museum has two similar winds: North and South as is shown in the drawn of Fig. 2.

\subsection{Roof composition}

The new cover designed is an "inverted cover" composed of a multilayer system in which the upper cover is lead and the rest of the layers are listed in the caption of Fig. 3. The roof had an inclination for water draining of $1.5 \%$. Although it is a multilayer system the only coat with barrier responsibility was the liquid waterproofing material named SIL (Fig. 4 left part): it is a aqueous dispersion of an acrylic copolymer that it is applied in layers as a liquid which hardens and that make a bonding with the support. It is a bi-layer having in the middle a glass textile to reinforce it (Fig. 4 centre). This waterproofing coat is applied on a support made by a mortar with lightweight aggregates and is covered by a rubber as is shown in Fig. 4 left. The rest of the layers are on mortar, thermoformed polystyrene (for thermal isolation), geotextile and, the final lead coat. Only the SIL was designed to be full waterproofing while the lead cover and the rubber and geotextile, were not designed to overlap in such a manner that could have been also tight. This is theoretically correct due to the ease to apply the liquid waterproof, its continuity and adaptation of irregular geometries. However, it is very difficult a full control of the thickness of the polymer applied and the correct execution of the entire singular and intersection points that the roof has.

The thermoformed polystyrene for the thermal isolation was composed of panels of $1250 \times 600 \times 50-40 \mathrm{~mm}$, in size with a thermal resistivity $1.80 \mathrm{~m}^{2} \mathrm{~K} / \mathrm{W}$. Their bottom parts were not splinted in order to allow rapid evacuation of the water.

With respect to the lead coat, it was designed as a finishing cover without tight function. Its thickness was of $1.5-2 \mathrm{~mm}$ and was placed with a certain overlapping but not enough to assure the tightness. Due the roof is an inverted cover and in which the components are inverted with respect to the traditional roofs, it can be executed more rapidly than the traditional ones (a movable special temporal cover that can be identified in Fig. 1 centre was installed during the works) and it works also a vapour barrier.

\subsection{Leaking event}

During the execution of the refurbishment works a very important storm with very much raining was produced. After it, several moist zones were recognized underneath the roof and a leaking event appeared in the hall where the famous paint "Las Meninas" from D. Velázquez is held. The information provided was that the zone where this leaking event was produced was not under work but had been finished around one year before and then, the water to arrive to the interior had to permeate at the intersection of a skylight through the lead cover and the entire multilayer roof and running throughout the floor underneath, it was leaking into that hall.
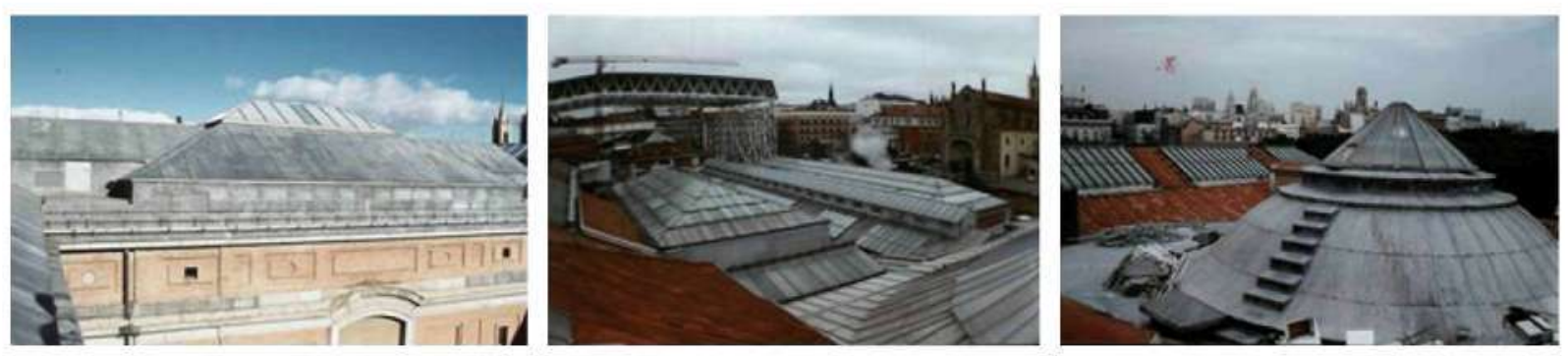

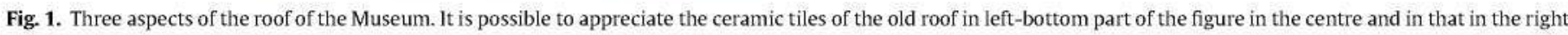
part. 


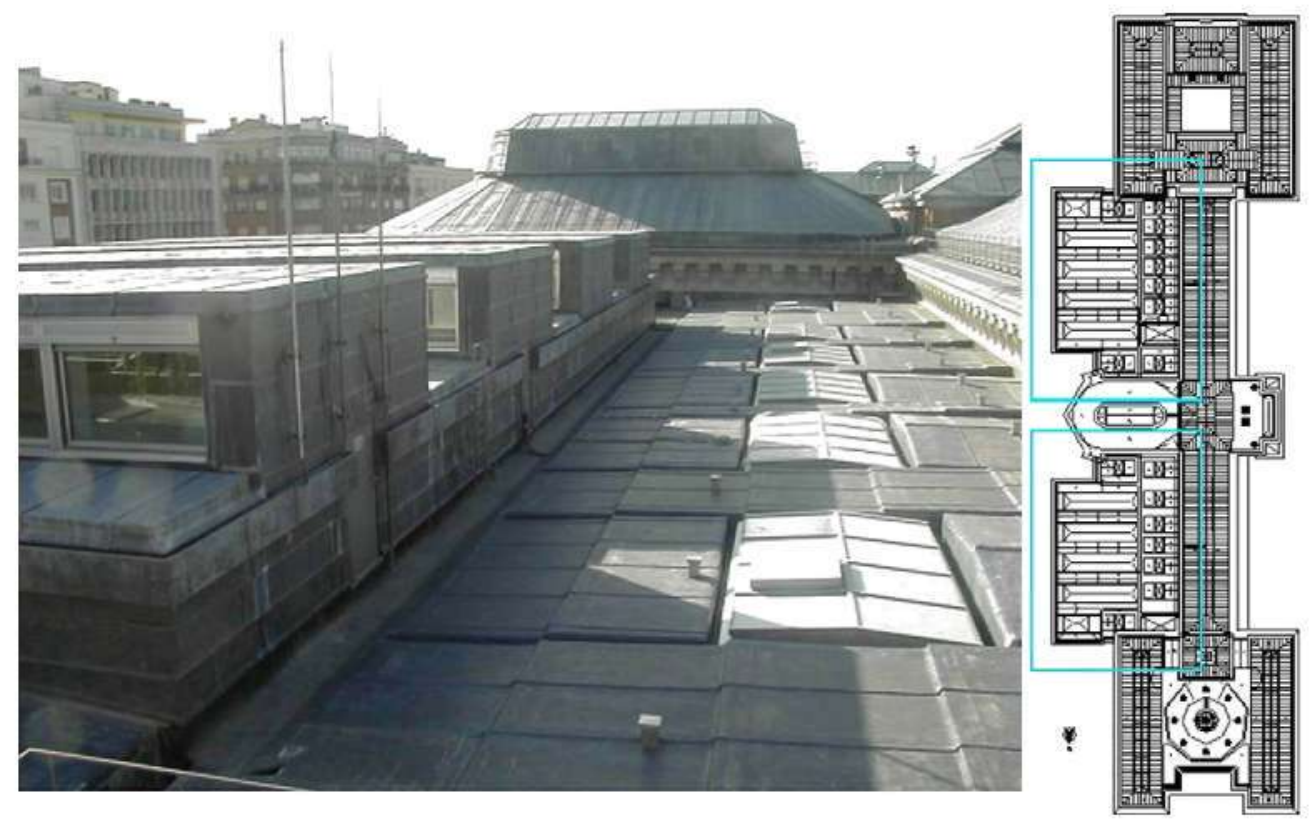

Fig. 2. In the left is shown the aspect of the roof of the Museum with the lead cover and in the right is given the lay-out of the roof.

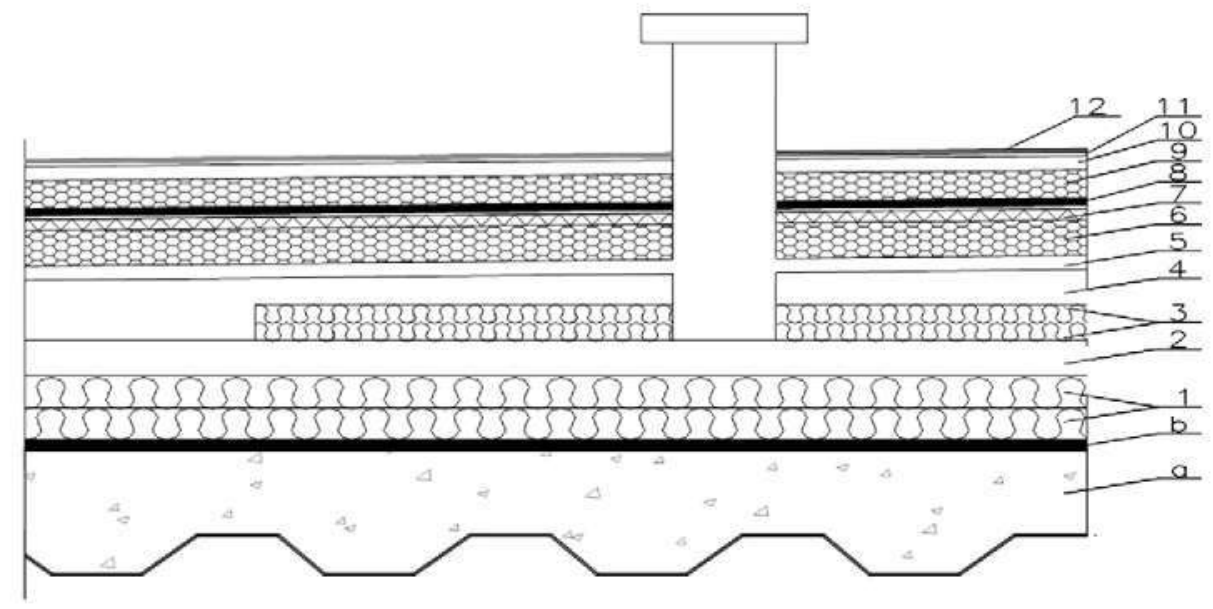

Fig. 3. Elevation corresponding to the roof section: (a) concrete, and (b) liquid waterproofing (SIL). (1) insulation, (2) cement mortar, (3) insulation, (4) cement mortar, (5) vapour scattering layer (thermoformed polyethylene), (6) mortar with arlite, (7) liquid waterproofing (SIL), (8) floating waterproofing (rubber), (9) mortar with arlite, (10) cement mortar, (11) Geotextile, (12) Lead.
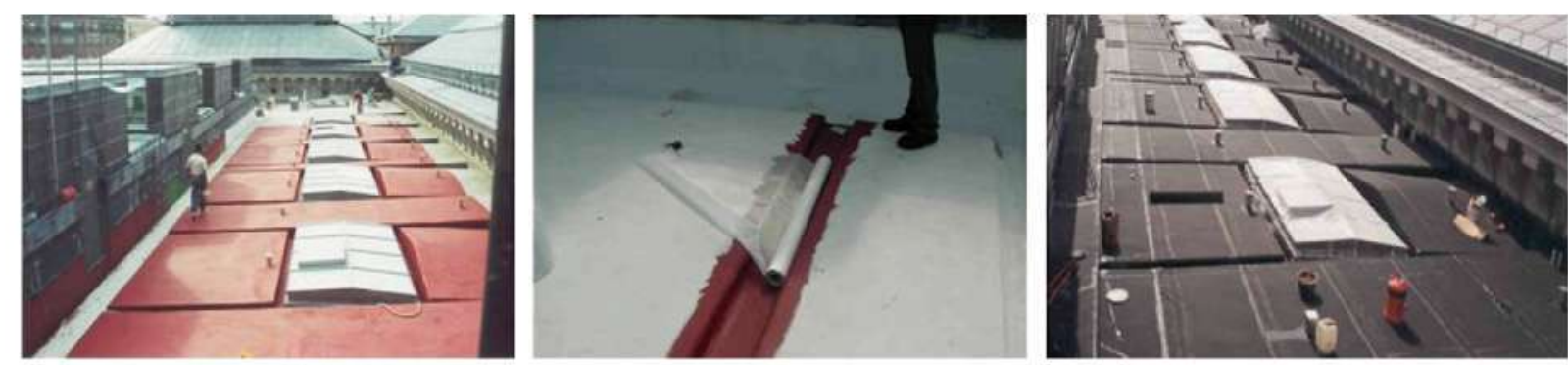

Fig. 4. Liquid waterproofing (SIL)

The event was explained due to the lack of enough evacuation ability of the draining horizontal and vertical pipes (Fig. 5) because of the enormous amount of water dropped during the storm. Due to the small inclination (although fulfilling the standards) of the roof and the large surfaces (of around $1100 \mathrm{~m}^{2}$ in the zone of the leaking) of the roof (Figs. 1 and 2), the water is accumulated after a rain event, even not important (Fig. 6 left taken during one inspection), and therefore could not be evacuated with enough speed remaining as scattered "ponds" during certain hours all around the roof. In addition, during the exhaustive inspection there were found some local execution defects (Fig. 6 right) that were statistically feasible due to the extraordinary complexity of the 

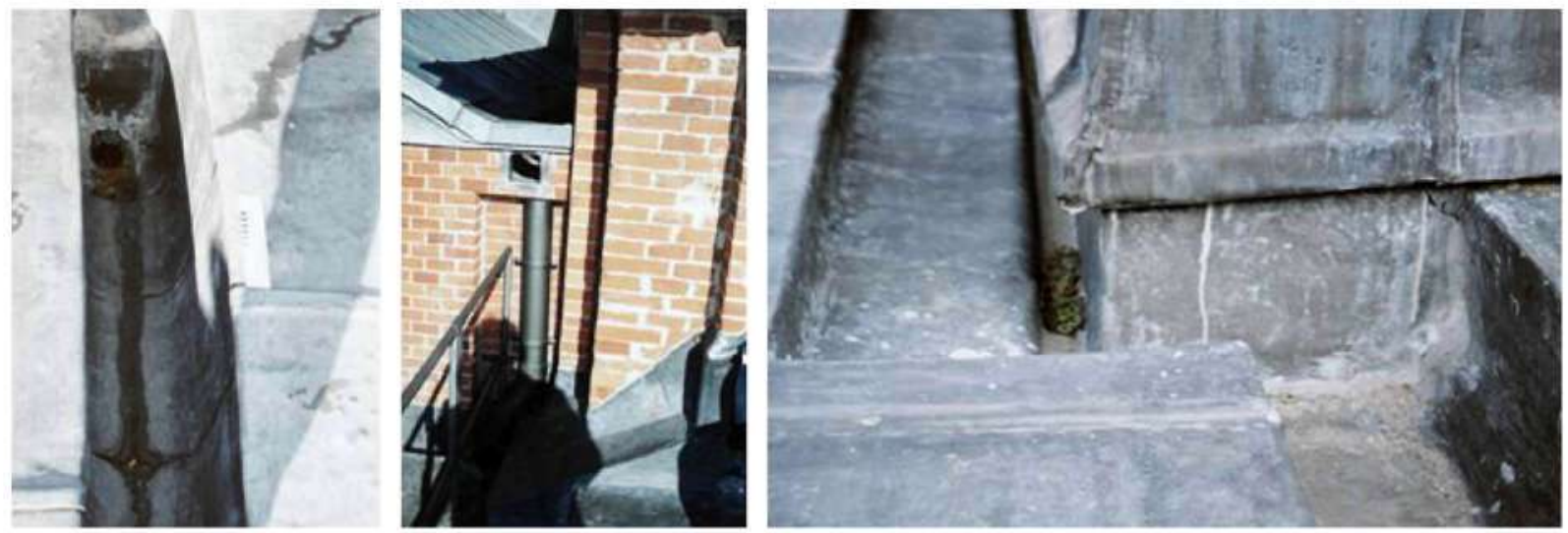

Fig. 5. The draining horizontal and vertical pipes.
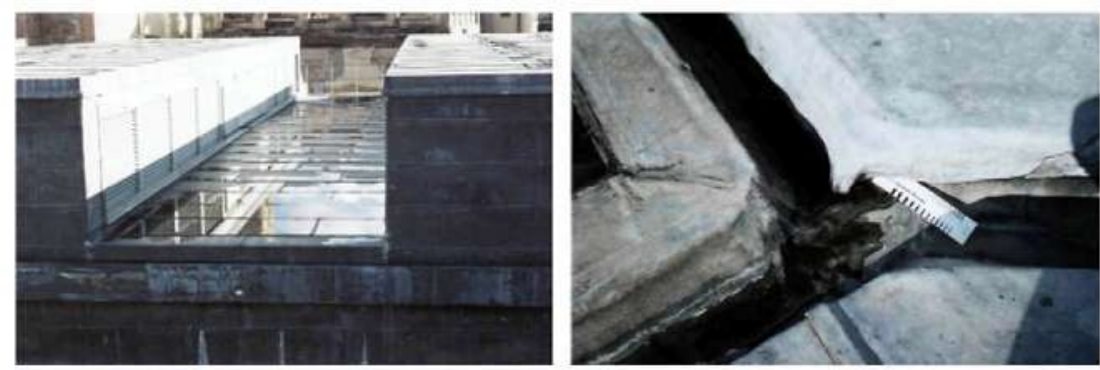

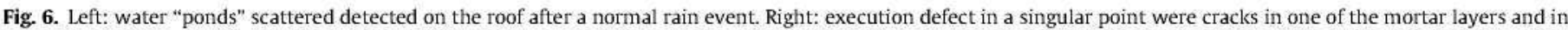
the rubber were found.

roof with numerous singular and intersections points. In summary, the leaking was attributed to the generation of a local pond due the lack of section of the draining pipes for evacuation of the rain dropped, with the simultaneous coincidence of a local defect found in the waterproofing coat at the border of the skylight affected.

It is not the aim of present paper to describe all the details of the reasons of the leaking but to justify the recommendation of the continuous monitoring system installed and of the recommendations made to improve the tightness and water evacuation ability of the roof. The roof was exhaustively inspected and all execution defects found were repaired (Fig. 7). The inclination of the roof was increased in certain zones and the vertical draining pipes were increased. As part of the repairing a monitoring system of the roof tightness was proposed and accepted. No new leaking event has been detected since then.

\subsection{Monitoring system}

The purpose of the system was to monitor the tightness and hydrothermal performance of the roof. The sensors had to be de- signed so that they could be embedded at different layers of the multilayer system without affecting its tightness in any manner. No similar sensor system has been found to be reported in the literature, due to the roof system is fully original and the thickness of each roof layer is very thin.

\subsection{Sensors}

Four types of sensors were selected to be embedded in the roof, one of which (the water detectors) were specifically designed:

1. Temperature sensors (Type A) were commercially available. Their operating temperature is $-50 / 500^{\circ} \mathrm{C}$ with an accuracy of $\pm 1{ }^{\circ} \mathrm{C}$ (Fig. 8 , left).

2. Relative humidity sensors (Type $C$ sensor) are also commercially available. They are capacitive, and two models have been used. The first measures the relative humidity in a range of $0 / 100 \%$ of relative Humidity, $\mathrm{RH}$. Its accuracy is of $5 \%$ (at $100 \% \mathrm{RH}$ ) and its operating temperature is $-20 / 80^{\circ} \mathrm{C}$. Within the same capsule, it has a temperature sensor that, with an accuracy of $\pm 0.75^{\circ} \mathrm{C}$,
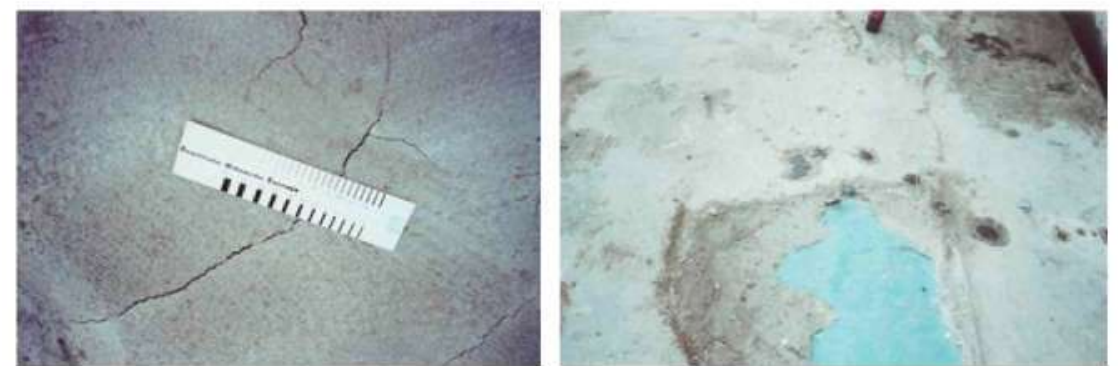

Fig. 7. Roof defects repaired. 

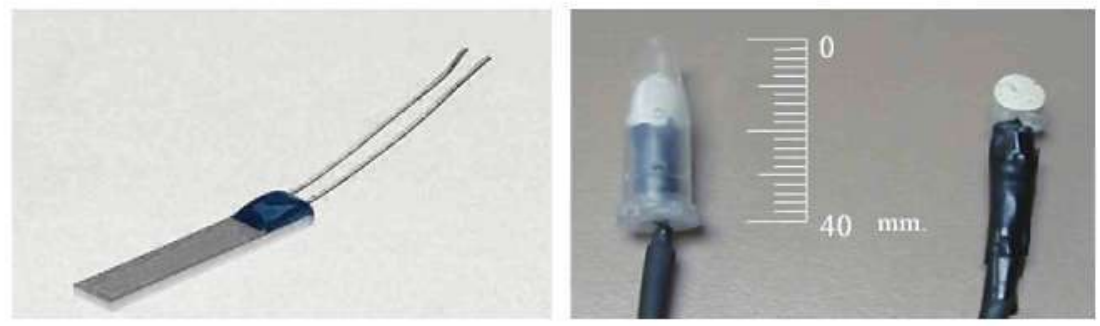

Fig. 8. Left: temperature sensor. Right: liquid water sensors.
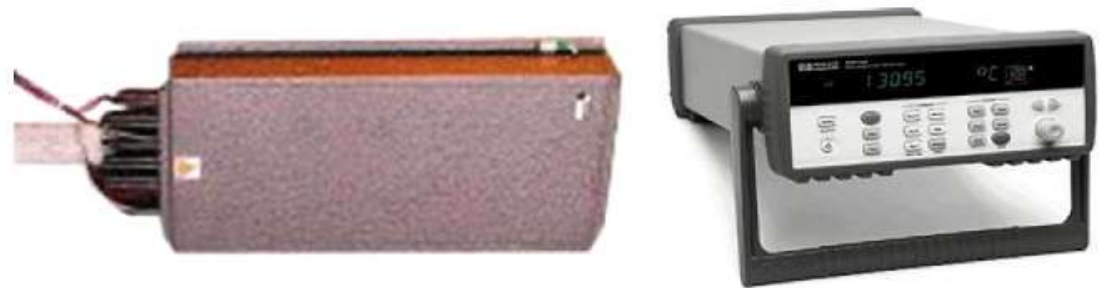

Fig. 9. Data Logger system.

allows for compensating the reading throughout the entire temperature margin. It has not almost hysteresis and is not saturated when reaching $100 \% \mathrm{RH}$. The other sensor type used has also a nominal measuring interval of $0 / 100 \%$ with an accuracy of $2 \%$ and the operating temperature is $-40 / 85^{\circ} \mathrm{C}$. However when reaching $100 \% \mathrm{RH}$ it saturates and takes very long its recovery.

3. Strain is measured by the embedding of strain gauges (Type D sensor). The gauges suitable for being used in polymeric materials for large strains, were $5 \mathrm{~mm}$ in long, with a resistance of $120 \Omega$ and a gauge factor of 2.09 , with a cross sensitivity of $0.1 \%$ and a temperature compensation of $5 \times 10^{-6} /{ }^{\circ} \mathrm{C}$.

4. Liquid water sensors (Type B sensor), which were specifically designed for this case. They detect the presence of liquid water by means of a measurement of potential drop between two electrodes and therefore based in the generation of a potential difference when a certain amount of liquid water is present in the media. The sensor response to the presence of water is relatively quick. The potential reaches values of around $850 \mathrm{mV}$ approximately one to two minutes after the sensor is dampened (Fig. 8, right).

The monitoring system was composed of a interface and a Data Logger shown in Fig. 9. The measurements have been taken using a data acquisition and switching unit (Data Logger). This device has an internal memory for data storage, which means it can operate independently, that is, without a computer. Furthermore, the data acquisition configuration is maintained even in the case of power failures. The data stored are periodically downloaded into a laptop by using a program that also allows for setting up the Data Logger's 60 channels. The Data Logger error, which includes measurement, switching and transducer conversion, is: voltage: $4 \mathrm{mV}$ on the $1 \mathrm{~V}$ scale; RTD: $0.06{ }^{\circ} \mathrm{C}$ on the -200 to $600{ }^{\circ} \mathrm{C}$ scale; resistance: $0.01 \Omega$ on the $100 \Omega$ scale.

\subsection{Location of sensors}

As it was unknown whether the cables of the sensors which transverse the whole roof until the recording unit, could be a path for rain water penetration, only one location in each North-South roof winds were selected for the monitoring system (Fig. 2). The places looking the weakest regarding roof tightness were selected for the installation of the sensors. That of the North wind was switched off and dismantled after a certain time of working due to the results were identical than the results of the South wind and due the Museum authorities did like the less possible disturbance. In the South wind the most critical location identified was just were the leak was produced, and then it is over the hall where Las Meninas paint is exhibited. The results given in present paper are those of the South wind which continue recording data.
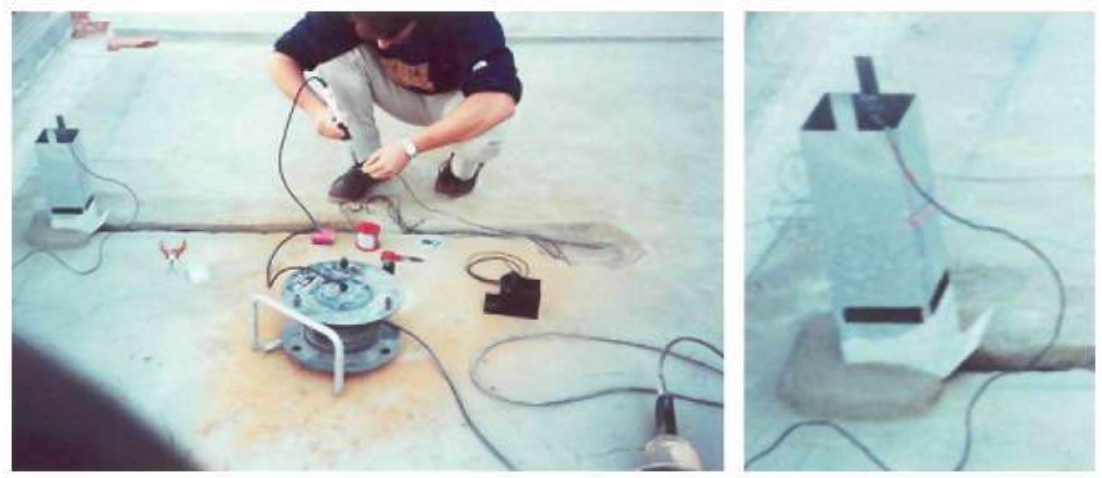

Fig. 10. Sensor location and installation. 
Table 1

Sensors installed in the roof

\begin{tabular}{llll}
\hline Sensor & Sensor type & Sensor & Sensor type \\
\hline A01 & Temperature & B26 & Liquid water \\
B01 & Liquid water & A17 & Temperature \\
A12 & Temperature & B17 & Liquid water \\
B12 & Liquid water & C17 & Relative humidity \\
A22 & Temperature & D17 & Strain gauge \\
B22 & Liquid water & A27 & Temperature \\
A13 & Temperature & B27 & Liquid water \\
B13 & Liquid water & D27 & Strain gauge \\
A14 & Temperature & A18 & Temperature \\
B14 & Liquid water & B18 & Liquid water \\
A24 & Temperature & C18 & Relative humidity \\
B24 & Liquid water & A28 & Temperature \\
A15 & Temperature & B28 & Liquid water \\
B15 & Liquid water & C28 & Relative humidity \\
A25 & Temperature & A19 & Temperature \\
B25 & Liquid water & B19 & Liquid water \\
A16 & Temperature & C19 & Relative humidity \\
B16 & Liquid water & A29 & Temperature \\
C16 & Relative humidity & B29 & Liquid water \\
A26 & Temperature & C29 & Relative humidity \\
\hline
\end{tabular}

The sensors were positioned during the refurbishment work (Fig. 10). The liquid water and temperature sensors were placed between each one of the roof layers and in two different positions, with one close to a "breathing" chimney (Fig. 10) and the other further away. Being designed as the main barrier against rain water, the strain gauges were placed on the waterproofing membrane layer-SIL-(Fig. 3) in order to monitor its performance with respect to the risk of cracking. The relative humidity sensors were placed at several positions in the waterproofing layer and below the surface lead layer.
Table 1 lists all the sensors installed in the roof. The letter corresponds to the type of sensor, the first digit indicates one of two possible positions within a height or layer, and the second digit indicates the roof layer it is on. Fig. 10 shows the arrangement of the sensors closest to a chimney.

\section{Results}

Fig. 11 presents the complete record of temperature readings for one of the two sensors located below the lead layer. The graph plots the annual temperature cycles and daily variations. This is the position that records the widest temperature variations, exceeding $50^{\circ} \mathrm{C}$ in summer and dropping below $0{ }^{\circ} \mathrm{C}$ in winter.

Fig. 12 shows the temperature variation in two sensors located at different heights. Whereas the sensor closest to the roof surface records major daily variations, the sensor that has been embedded the furthest down (A01) remains almost constant.

Fig. 13 plots the temperature readings recorded by all temperature sensors against time and depth. The sensors closest to the surface record a large temperature variation due to ambient temperature variations and sunlight, whereas the further down embedded, shows the smaller variations in temperature. These parameters indicate that the refurbishment work has been performed correctly with proper insulation.

The recording of the RH values is depicted by Fig. 14. As reported in [25], the relative humidity inside concrete may remain at values above $60 \%$ during long periods, which means that condensation may appear in certain places, such as, for example, between the floating waterproofing layer and the arlite mortar where it is noticed by the liquid water sensors.

The strain-gages monitor the strain of the polyurethane waterproofing membrane, called SIL layer.

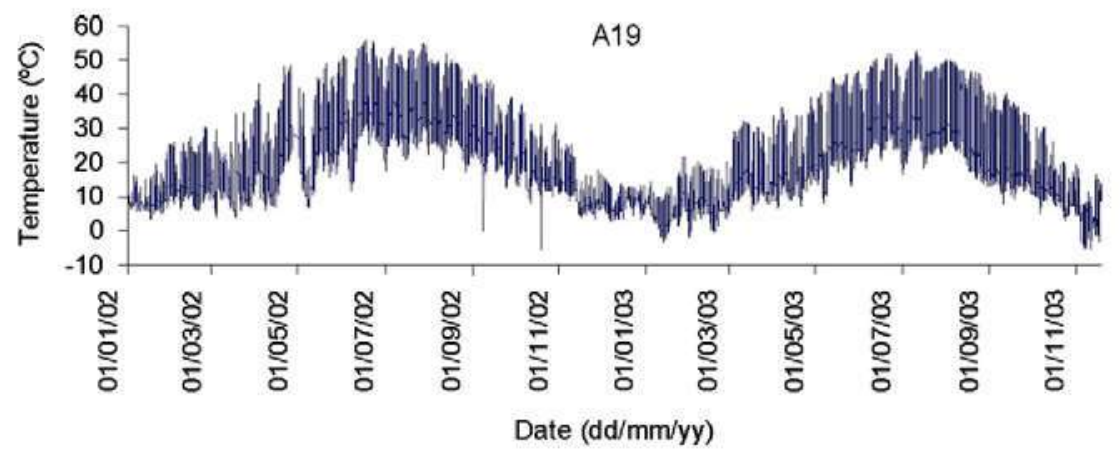

Fig. 11. Temperature sensor A19, located in position 1 and on layer 9.

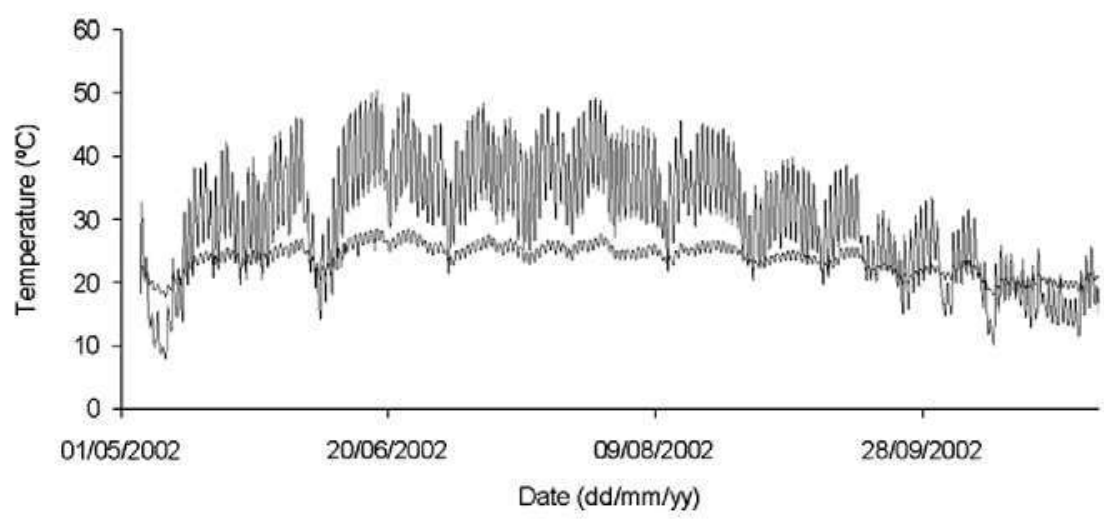

Fig. 12. Comparison of the temperature at two different depths. A01 and A15 temperature sensors. 

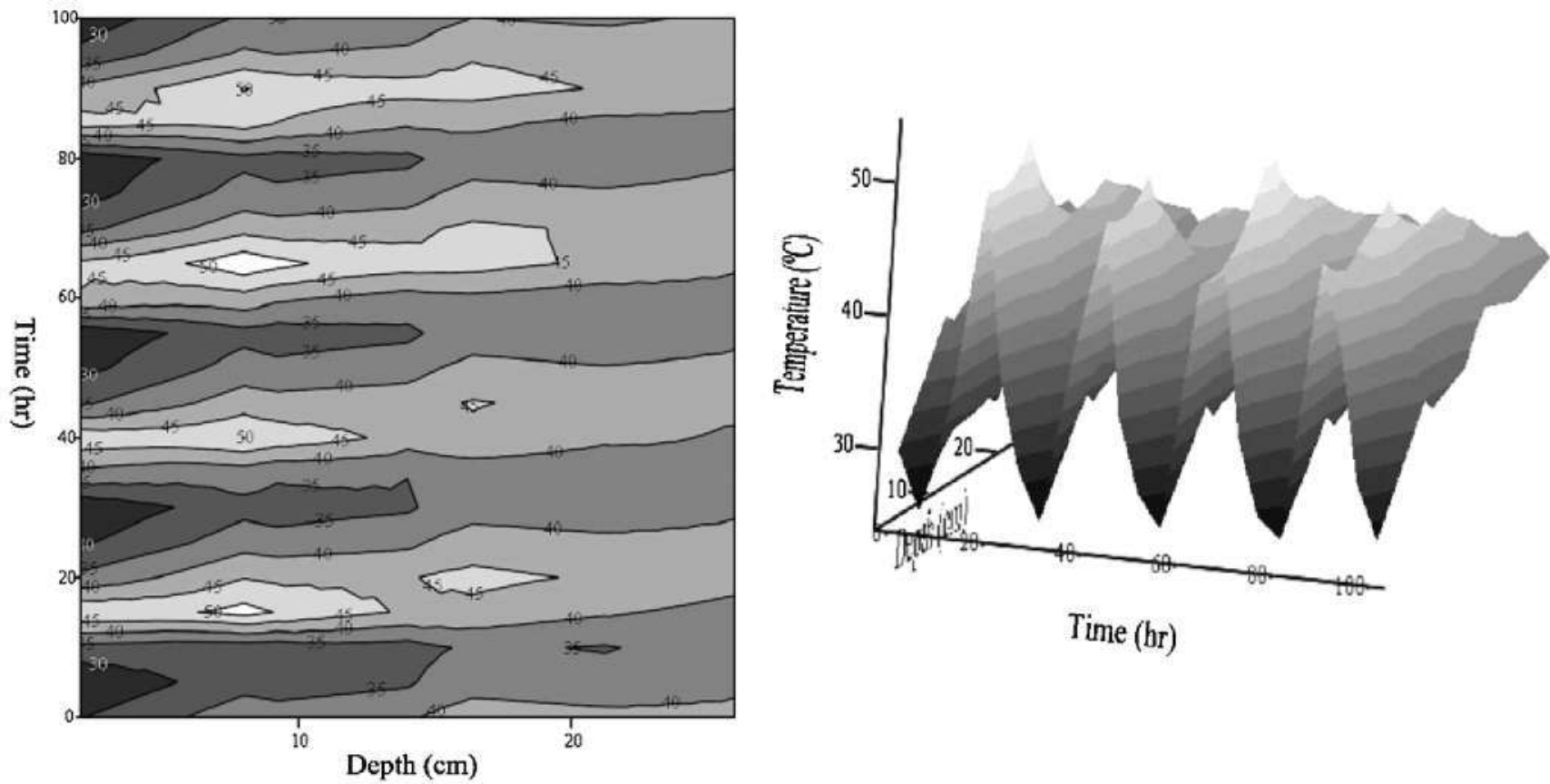

Fig. 13. In the left is given temperature gradient with depth of the roof. Daily variations. In the right is shown these variations with their evolution in time.

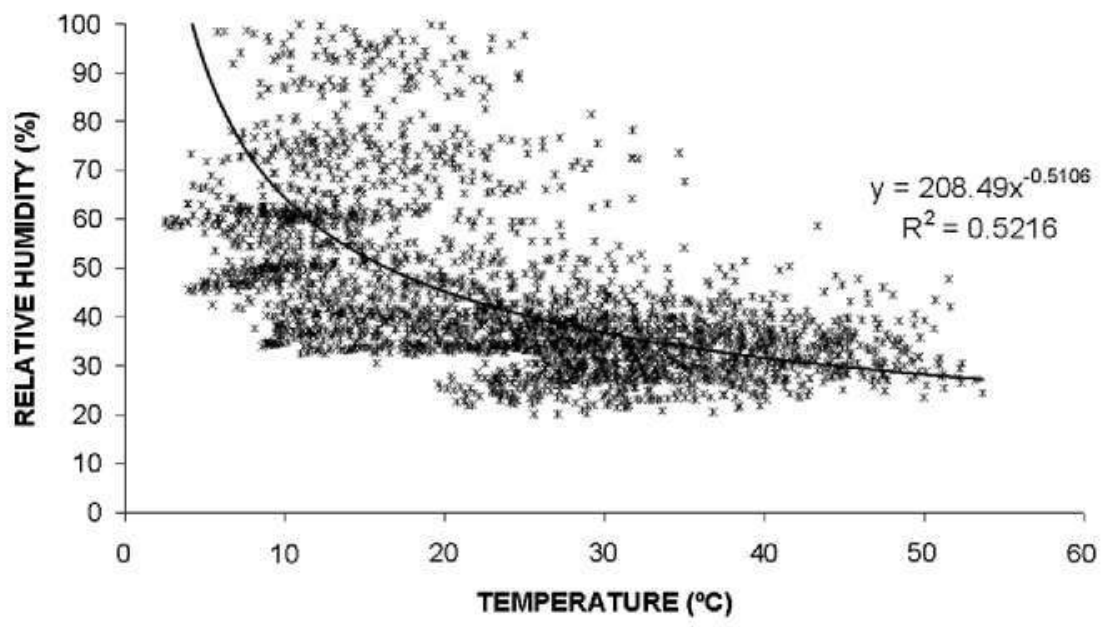

Fig. 14. Relative humidity values obtained from the sensors and their relation to temperature.

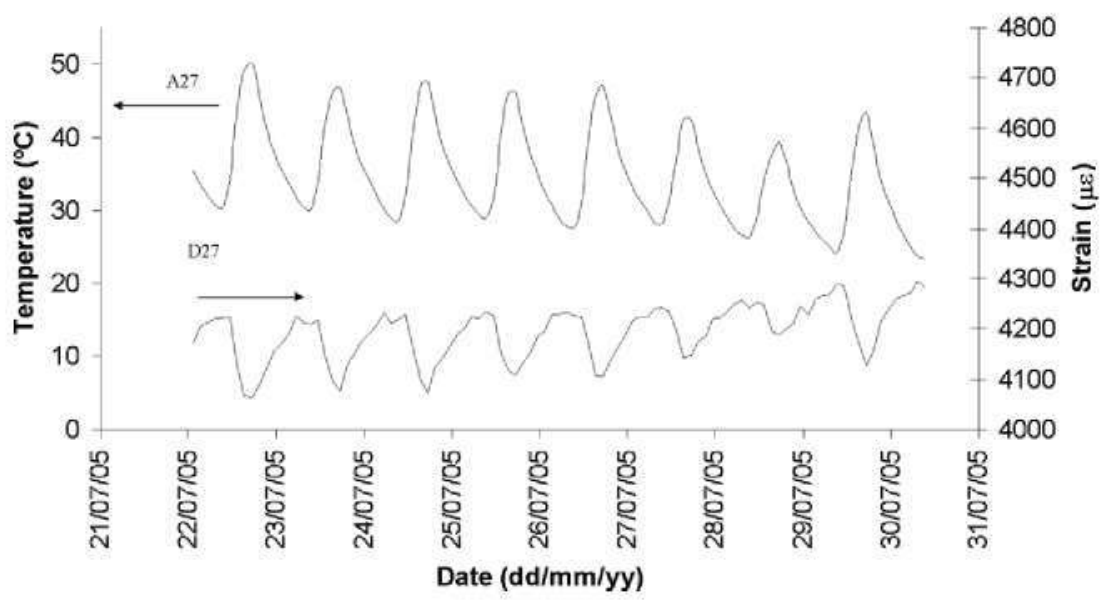

Fig. 15. Variation in the strain of the sealant plotted simultaneously to temperature. 


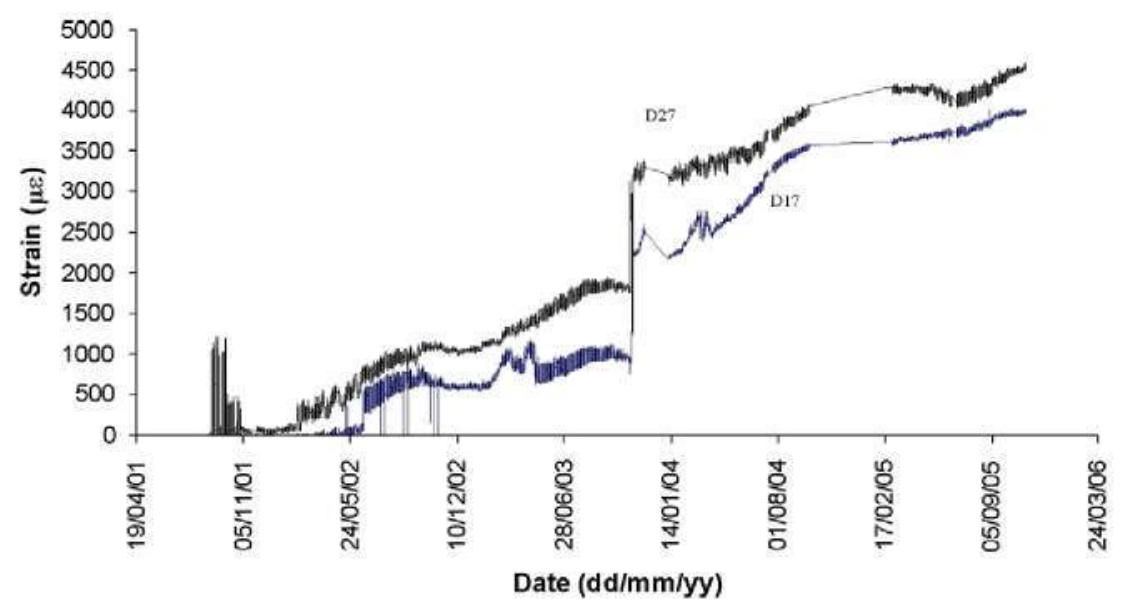

Fig. 16. Strain values recorded from strain-gages positioned in the sealant.

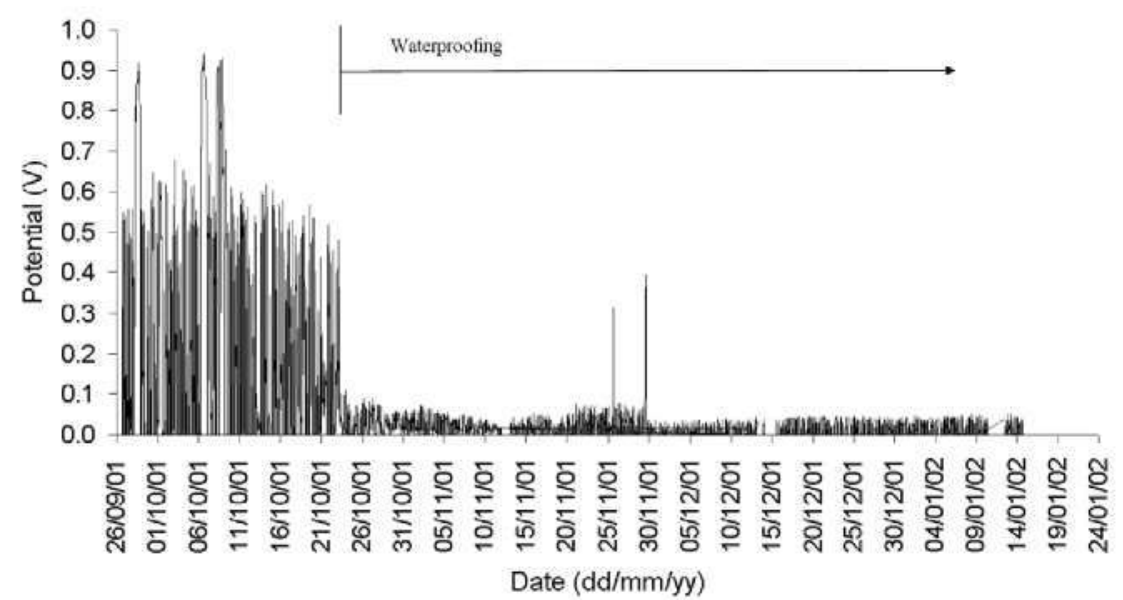

Fig. 17. Liquid water sensor showing at the beginning high changes in potential difference while these differences disappear when drying.

Fig. 15 provides a detail of the daily variations in strain and the temperature reading of the sensor located besides the gauge. There is a dimensional variation in the waterproofing layer caused by changes in temperature. The absolute amplitude variation is around $200 \mu \varepsilon$, that is, a strain of $0.02 \%$, which is a very low figure, and even more so for a polymeric material. More important seems to be the permanent increase in strain that is depicted by Fig. 16. The gauges indicated certain cycles during their installation to further increase continuously with the time, as if the system is expanding. A vertical shift of the reading noticed at the end of

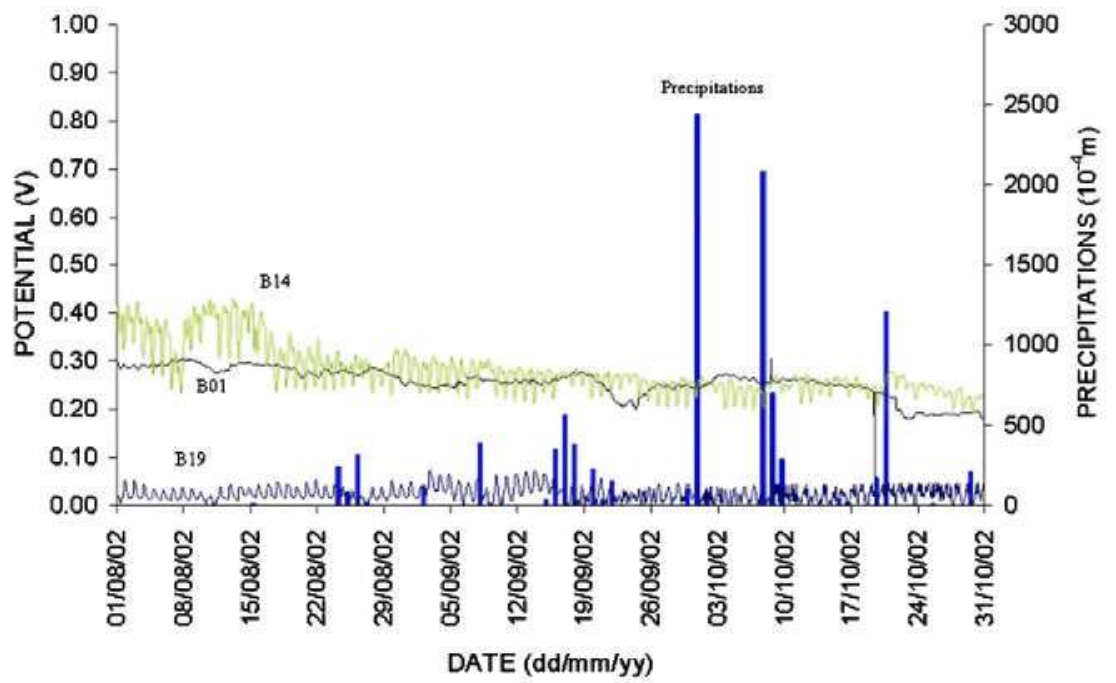

Fig. 18. Precipitations and potential difference given by liquid water detecting sensors, 
2003 has to be interpreted as due to a voltage jump due to the switching off-on for the downloading of the data occurred at that time. The further recording was logical if this shift is neglected, and then this sharp variation did not alter the recording.

The liquid water sensors that have been installed in all the roof layers during its refurbishment were specially manufactured for this work. Fig. 17 presents the readings of one of the liquid water sensors during the period it was installed. This sensor was embedded in the liquid waterproofing until the floating waterproofing was put in place. It can be noticed through the initial high values of potential difference, how it detects the presence of water, as that exposure coincided with a period of rainfall, until the time when the floating waterproofing was installed, in which moment the potential difference decreased dramatically due to this last layer effectively isolated from the rain.

Additional information is given in Fig. 18 which shows the rain precipitations and the behaviour of some liquid water sensors placed in different roof layers. In this example, the rain precipitations are not detected by the sensors. This is interpreted as the rain water does not ingress into roof layers being then the system operating as expected.

Finally Fig. 19 presents the average values recorded by the liquid water sensors. The values remain almost constant over the four years of registering. All the sensors record potential values below $0.8 \mathrm{mV}$, that is, they do not detect the presence of liquid water

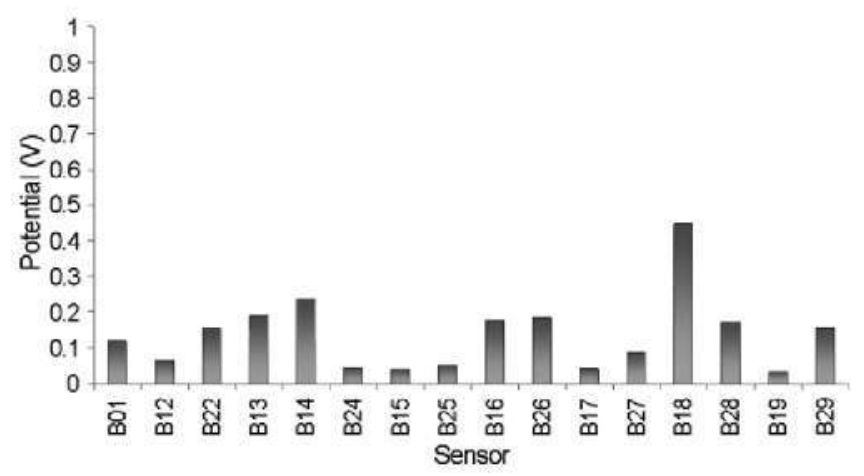

Fig. 19. Averaged value of the potential difference of the liquid water detecting sensors during the 4 years. inside the roof at any of its layers. The different value readings between the sensors are due to their positioning. The sensors placed in contact with the mortar have a higher potential difference than all the other sensors. This was interpreted to be due to the relative humidity within the cementitious mortar is higher, which may cause condensation in certain places when the temperature lowers.

\section{Discussion}

The study had as main goal to monitor the roof performance with respect of its tightness ability and its hydrothermal behaviour. As additional information it was also interesting to analyse the durability and suitability of the sensors because there are very scarce the experiences of monitoring moisture in historical buildings and less those studying specifically the layers of a roof or its hydrothermal performance.

Madrid has a climate with relatively well marked seasons. It has a dry atmosphere which reaches values between 10 and 30\% RH in summer lasting from June to September where the rain seldom appears. Autumn and spring may be relatively mild (averaged $T \cong 15^{\circ} \mathrm{C}$ ) with intermittent rain periods and winter temperatures are usually around $5-10^{\circ} \mathrm{C}$, although occasionally temperatures below $0{ }^{\circ} \mathrm{C}$ and snow periods, may appear. The development of relatively extreme climatic conditions (below $0{ }^{\circ} \mathrm{C}$ and above $30^{\circ} \mathrm{C}$ ) makes Madrid climate a rather good example of Mediterranean climate with the risk of intense rains in several occasions.

Regarding water tightness, Fig. 14 shows the relative humidity values versus temperature. The roof behaves similarly to a closed system in which there is no incoming or outgoing humidity. The relative humidity drops as temperature increases, with absolute humidity, namely, the amount of water in the roof, remaining constant. This behaviour is not affected by periods of dry or wet weather. This confirms that not new water or vapour penetrates into the roof which then, maintains its tightness until present.

The water tightness has been also deduced from the sensors named "water detectors" because they progressively have dried and remain drying (Figs. 18 and 19) after they were wet at the initial mixing. These water detectors seem more adequate in present case than the RH sensors. The RH sensors are commercial and easy to install and control but they cannot inform on the phenomena of condensation or the presence of liquid water because when the reaching of $100 \% \mathrm{RH}$ is compatible with both: (a) the presence of

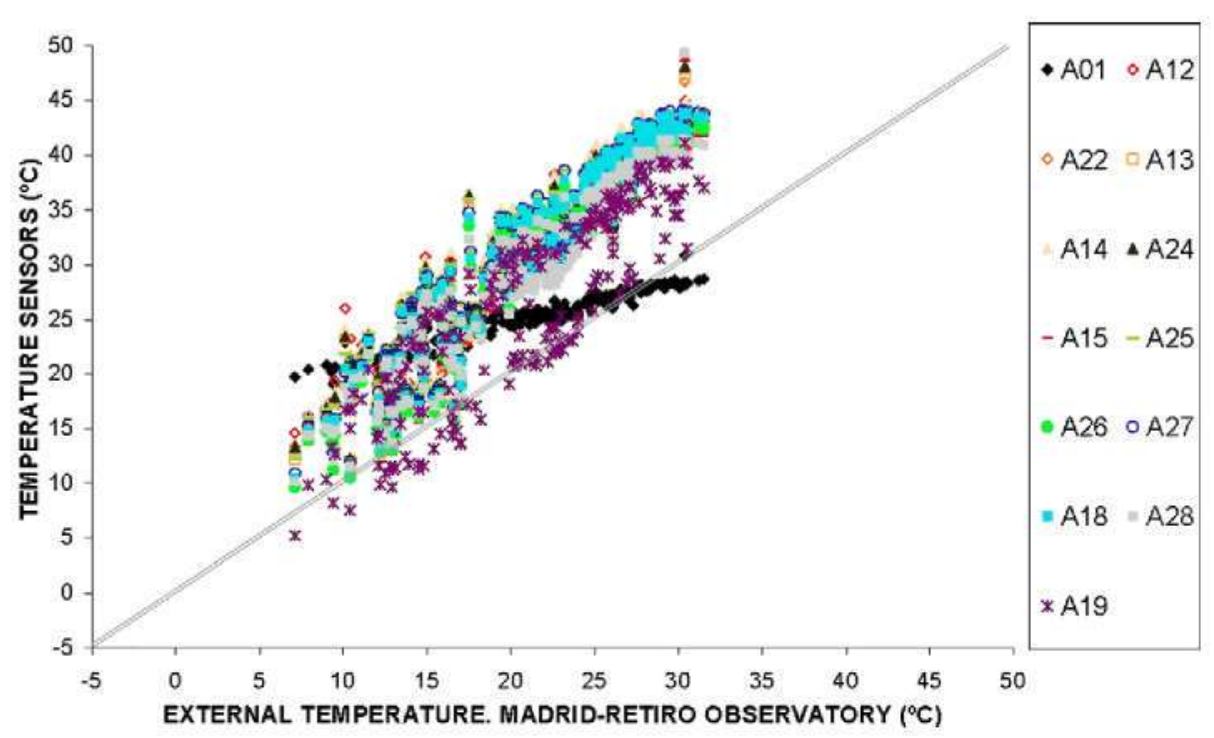

Fig. 20. External and sensor roof temperatures. 
water vapour until saturation of the air in the roof layers spaces which may be reached simply by lowering the temperature to reach condensation and (b) the presence of new liquid water coming from the rain on the roof which also would be indicated by 100\% RH. They are not able to distinguish between both circumstances: condensation by temperature lowering or by the penetration of rain water. However the liquid water detectors give a scale in potential drop which accounts on the amount of liquid water in the media. Then condensate water by temperature lowering gives very small potential difference while rain water will increase the potential drop between the electrodes of the sensor. Then these sensors are sensitive to possible rain leakages while those of $\mathrm{RH}$ could mislead the deductions as $100 \%$ RH can be achieved simply by a temperature lowering during night or in low temperature periods.

With respect to the thermal behaviaur of the roof, in Figs. 11-13 the temperatures are plotted with respect to the roof depth and the time. Better appreciation is possible in Fig. 20 where external and roof temperatures are compared. It is necessary to remark that in general the temperature of the roof is higher than external temperature, being around until $15^{\circ} \mathrm{C}$ higher than the external temperature. This phenomenon is interpreted to be caused by solar radiation and thermal hysteresis due to the lead cover which stores the heat and provokes its slow release. Hоwever when penetrating into the most internal roof layers the temperatures decrease significantly although and the temperature іл the most interior layer remains stable and around $20^{\circ} \mathrm{C}$ (Figs. 12 and 20) which is indicative that the roof is isolating from the external temperature changes and is damping the thermal charge. Contraty, the internal temperature of the roof is higher than the exterior in winter, when the external temperature is almost $0^{\circ} \mathrm{C}$ and the internal temperature remains in about $20^{\circ} \mathrm{C}$.

With respect to the performance of the material called SIL which was designed by considered the only barrier towards the rain water, it seems to work adequately with respect to permeabiljty, as the results collected until now indicate that water has not penetrated the SIL. Being this material of polymeric nature, it should be elastic enough to avoid cracking when expands due to the temperatures changes. With respect to its behaviour, the strain gauges indicate that is elastically deforming following the temperature changes and is linearly straining with time which is interpreting that it seems to be thermoplastic or viscoelastic behaviour. Its permanent straining with time recommends the maintenance of the monitoring longer times to follow a possible aging or cracking.

Finally, with respect to the sensors themselves, they have performed very well as all, except some few measuring RH, give correct signals until now and those manufactured at the laboratory (liquid water detectors) seem to have a promising sensitivity with respect to presence of liquid water. Then, the monitoring system designed is adequate to fulfil the objectives planed on the monitoring of the roof water tightness and SIL aging. It has been able also to indicate the temperature isolation abilities.

\section{Conclusions}

El Prado Museum suffered a refurbishment involving the change of the old roof by a new one using modern and old materials combined iл a multilayer roof. During the works a leaking of water was detected in the hall where Las Meninas by Velazquez are exhibited which created a social alarm and questioned the adequacy of the new roof. The inspection made detected two main problems justifying the leakage: ал ілаdequate ілclination of the roof which was corrected and a lack of correct detailing of the vertical and horizontal intersections in the roof which were all of them repaired. A monitoring systems based in the embedding of sensors in the different layers of the roof was designed and located in one sone of the North and the South winds of the Museum. The conclusions reached of the analysis of the results of the South wind sensors during the first 4 years of monitoring are the following:

1. Almost all the sensors have performed well, albeit few recording relative humidity, have failed to operate during this time.

2. The water tightness of the whole roof is maintained and the changes іл RН noticed іл the different layers are attributed to the changes in temperature

3. The water detector sensors specifically designed for the trial give correct indications that the water sensed is due to the mortar being one of the layers and that the roof is drying by progressive hydration of the mortar with time.

4. The temperatures in the roof are around $15^{\circ} \mathrm{C}$ higher in summer iл the external parts of the roof than the ambient ones which is attributed to the external metallic cover while in winter the temperatures in the external part may be as low as some degrees below zero. With respect to the isolating ability of the multilayer roof, in summer it is very efficient as the sensors of the internal layer show stable and adequate mild temperatures not been affected by external changes and then being damping the thermal charges.

5. Finally with respect to the polymeric material called SIL used as the main water barrier, it seems to perform elastically with daily and seasonal temperature changes bit shows to be linearly deformed with time which is indicative of a viscoelastic or thermoplastic nature. Its aging is crucial for the durability of the water tightness of the roof.

The overriding conclusion considering the above results is that the roof behaves in a proper manner, as the water detectors sensors reveal that there has bеen no incoming moisture from the outside into the inner layers on the roof, specifically, into those below the liquid waterproofing. These sensors seem to be a promising manner to control the water tightness ability of the roof.

\section{Acknowledgements}

The authors would like to thank the Мanagement of Infrastructures and Installations of the Ministry of Culture of Spain. We are grateful as well to Javier Barroso and Gabriel Rentero from IETcc for their help in the monitoring system. They acknowledge as well the financing of the same Ministry through the INGENIO 2010CONSOLIDER Project on "Safety and Durability of Structures: SEDUREC".

\section{References}

|1| Sanchez-Beitia S. Brebbia CA. STREMAH 97; structural studies, repairs and maintenance of historical buildings. Ind Ceram 1997;17(3):196-7.

|2| Matos JC et al. Structural Health Monitoring (5HM) system implemented in Sorraia river bridge. Appl Stat Probab Civil Eng 2007:75-7.

[3| Matos JCE et al. Health Monitoring System (HMS) for structural assessment. Smart Struct Syst 2009;5(3):223-40.

[4] Anzani A et al. Evaluation of the repair on multiple leaf stone masonry by acoustic emission. Mater 5truct 2008:41(6):1169-89.

[5] Glisic B et al. Monitoring of heritage structures and historical monuments using long-gage fiber optic interferometric sensors-an overview. In: Proceedings of the $3 \mathrm{rd}$ Intemational conference on structural health monitoring \& intelligent infrastructure: structural health monitoring \& intelligent infrastructure; 2007: p. U927-33.

[6] Damonte $G$ et al. Structural Health Monitoring on real scale model of a masonry triumphal arch. Damage Assessment Struct Vll 2007:347:279-84

[7] Casciati S. Monitoring data for the structural assessment of historical buildings. ln: Proceedings of the fourth European workshop on structural health monitoring: 2008, p. 227-33.

[8] Carpinteri A, Lacidogna G, Niccolini G. Acoustic emission monitoring of medieval towers considered as sensitive earthquake receptors. Nat Hazards Eartl Syst 5ci 2007;7(2):251-61. 
|9| Carpinteri A et al. Stability of the vertical bearing structures of the Sylacuse Cathedral: experimental and numerical evaluation. Mater Struct 2009;42(7): 877-88.

[10] Carpinteri A, Lacidogna G. Damage evaluation of three masonry towers by acoustic emission. Eng 5truct 2007:29(7):1569-79.

[11] Carpinteri A, Invernizzi S. Lacidogna G. Historical brick-masonry subjected to double flat-jack test: Acoustic emissions and scale effects on cracking density. Constr Build Mater 2009;23(8);2813-20.

[12] Carpinteri A, Invernizzi S, lacidogna G. Structural assessment of a 17thcentury masoniy vault with acoustic emissions and numerical techniques. Int J Archit Heritage 2007;1(2):214-26.

[13] Ohtsu M. Tomoda Y. Phenomenological model of corrosion on process in reinforced concrete identified by acoustic emission. Acta Mater J $2008 ; 105(2): 194-9$.

[14] Ohtsu M. Quantitative AE. Techniques standardized for concrete structures in acoustic emission testing. In: Pullin R et al., editors; 2006. p. 183-92.

[15] Ohtsu M. Basics of acoustic emission and applications to concrete engineering Mater Sci Res Int 1998:4(3);131-40.

[16] Anastasi G, Lo Re G, Ortolani M. WSNs for structural health monitoring of historical buildings. Hsi In: 2009 2nd conference on human system interactions; $2009,571-76$.
|17| Abu Zeid $\mathrm{N}$ et al. Indirect estimation of injected mortal volume in historical walls using the electrical resistivity tomography. J Cult Heritage 2010;1 1(2):220-7.

[18] Abruzzese D et al. Long life monitoring of historical monuments via wireless sensors nework. In: 2009 6th lnternational symposium on wireless communication systems (Iswcs 2009); 2009: p. 570-74.

[19] Martínez I, Andrade C. Examples of reinforcement corrosion monitoring by embedded sensors in concrete structures. Cem Concr Compos $2009 ; 31(8): 545-54$.

[20] Martinez I. Castillo A. Andrade C. Non-destructive electrochemical tecliniques applied to the corrosion evaluation of the liner structures in nuclear power plants. J Nucl Mater 2008;373(1-3):226-36.

|21| Andrade C. Martinez l, Castellote M. Feasibilicy of determining corrosion rates by means of stray current-induced polarisation. J Appl Electrochem $2008 ; 38(10): 1467-76$.

|22| Andrade C. Martínez I. Use of indices to assess the performance of existing and repaired concrete structures. Constr Build Mater 2009;23(9):3012-9. 